\title{
МЕТОДИКА НАСТАВЕ
}

\section{NENA A. VASOJEVIĆ ${ }^{1}$ \\ IVANA VUČETIĆ \\ SNEŽANA KIRIN}

Inovacioni centar

Mašinskog fakulteta u Beogradu
ORIGINALNI NAUČNI ČLANAK

UDK: $\quad 37.013 .31: 37.018 .43]$ :

373.3-051(497.11)

BIBLID: 0353-7129, 26(2021)1, p.27-38

\section{PROFILI NASTAVNIKA OSNOVNIH ŠKOLA U SRBIJI \\ PREMA OPREDELJENJU ZA NASTAVNI MODEL TOKOM PANDEMIJE COVID-19²}

\begin{abstract}
Rezime: Kvalitet nastavnog procesa u velikoj meri zavisi od nastavnika i njihovih kvalifikacija - uloga nastavnika je veoma značajna za uspešnu implementaciju novih nastavnih metoda. Ovaj rad je deo kvantitativne studije ispitivanja iskustva nastavnika osnovnih škola u Srbiji o radu u modelu onlajn nastave realizovanom tokom pandemije COVID-19, u poređenju sa tradicionalnim modelom nastave. Cilj rada je da se na osnovu iskaza i stavova nastavnika sagleda i definiše profil nastavnika u odnosu na izbor nastavnog modela koji im više odgovara za rad: profil nastavnika koji preferiraju isključivo tradicionalni model nastave i profil nastavnika koji preferiraju onlajn model nastave ili ne prave razliku u radu između ova dva nastavna modela. Pretpostavka je bila da će nastavnici koji imaju manje godina radnog staža, više stručnog usavršavanja i viši stepen obrazovanja preferirati onlajn model nastave. Za potrebe istraživanja konstruisan je onlajn upitnik iz dva dela. Prvi deo upitnika odnosio se na socio-demografske podatke, a drugi na karakteristike nastavnog procesa u zavisnosti od primenjenog modela. Za procenu uticprethodnih obuka na izbor preferiranog modela nastave korišćen je t-test nezavisnih uzoraka. Istraživanje je sprovedeno tokom januara i februara 2021. godine. Uzorak istraživanja činilo je 609 predmetnih nastavnika. Rezultati istraživanja pokazuju da izbor tradicionalnog ili onlajn nastavnog modela zavisi od toga koliko se nastavnik oseća kompetentnim za izvođenje onlajn nastave i od dužine trajanja prethodne obuke u okviru redovnog stručnog usavršavanja iz oblasti IKT-a. Rezultati istraživanja samo su delimično potvrdili početnu pretpostavku.
\end{abstract}

Ključne reči: tradicionalna nastava, onlajn nastava, profil nastavnika, kompetencije, COVID-19

1 nenavasojevic@hotmail.com,nvasojevic@mas.bg.ac.rs

2 Studija je realizovana uz podršku Ministarstva prosvete, nauke i tehnološkog razvoja, prema Sporazumu o realizaciji i finansiranju naučno-istraživačkog rada NIO za 2021. godinu. 


\section{UvoD}

Ovaj rad je deo šire kvantitativne studije koja se bavi ispitivanjem iskustva nastavnika osnovnih škola u Srbiji tokom realizovanja onlajn nastave u periodu pandemije COVID-19, u poređenju sa tradicionalnim modelom nastave. U ovom radu biće prikazani rezultati istraživanja koji uključuju prikaz i interpretaciju stavova predmetnih nastavnika.

Proglašenjem vanrednog stanja usled pandemije COVID-19 $9^{3}$ obrazovni sistem u Srbiji prvi put se našao pred izazovom da celokupni obrazovni sistem (,full-time”) bude preorijentisan na onlajn učenje na daljinu. Ovaj nastavni model razvijen je za kratko vreme i u početku se sprovodio sa ograničenim resursima (Vasojević i sar., 2020). Uvedeni onlajn nastavni model zasnivao se na upotrebi različitih veb-platformi (od eng. „World Wide Web” ili samo veb), kojima su učenici i nastavnici mogli besplatno da pristupe. Autori relevantnih naučnih izvora posebno ističu značaj metodološke pripreme pedagoga, koja u velikoj meri može uticati na efikasnost obrazovnog procesa tokom digitalizovanja nastave (Pavlović i sar., 2021).

Promene sa kojima se, usled prelaska na onlajn nastavu, suočavaju kako obrazovne institucije, tako i sami nastavnici, zahtevaju posebnu spremnost nastavnika i razvijanje sposobnosti kako bi se što uspešnije prilagodili novom načinu izvođenja nastave. Vaspitno-obrazovna uloga nastavnika u savremenoj nastavi je sve složenija i značajnija. Nastavnik ima obavezu da u svom radu prati promene u cilju unapređivanja i osavremenjivanja nastavnog procesa i podrške aktivnosti učenika.

\section{Promena uloge nastavnika U SKLADU SA DRUŠTVENIM RAZVOJEM}

Razvoj tradicionalne škole trajao je nekoliko vekova. Sa razvojem društva menjala su se i obrazovne institucije. Uloga nastavnika u tradicionalnoj školi zasniva se na prenošenju znanja, kontroli i proceni usvojenih znanja i postavljanju jasnih granica u ponašanju učenika u razredu (Lasić, 2015). Njegova uloga kao posrednika između nastavnih sadržaja i učenika je svedena na aktivnosti koje se najčešće sprovode kroz verbalnu komunikaciju. Uvođenjem novih tehnologija u nastavu menja se dinamika nastavnog procesa i beleže mnoge prednosti. Nastavni sadržaj predstavljen na ovaj način podstiče učenike da aktivno učestvuju u nastavi, čime se uvećava verovatnoća da će naučen sadržaj biti trajno zapamćen i efektivno primenjen u budućnosti, odnosno obezbeđuje bolje funkcionalno znanje (Wang, 2011; Maksimović i Osmanović, 2018).

Za razliku od tradicionalne nastave koja više računa vodi o nastavnom gradivu nego o učeniku i načinu usvajanja tog gradiva, savremena škola „zahteva”

3 Odlukom Vlade RS dana 15.3.2020. godine stupila je na snagu Odluka o obustavi izvođenja nastave u visokoškolskim ustanovama (Službeni glasnik RS, br. 30/2020). Učenici su novu školsku godinu (2020/21) započeli u školi, kroz neposredan obrazovno-vaspitni rad. Međutim, loša epidemiološka situacija zahtevala je primenu oba modela. 
diferencijaciju nastave i individualizaciju vaspitno-obrazovnog rada kako bi se što uspešnije realizovali ciljevi društva (Šejtanić, 2009). I pored ubrzanog menjanja društva, u školama se uglavnom insistira na gotovim znanjima i verbalizovanom učenju, što za današnje vreme nije dovoljno, već je neophodno razvijati opšte (ključne) kompetencije (Zobenica i Stipančević, 2018: 109). U praksi nastavnici teško prihvataju promene, nova pedagoška saznanja i tehničko-didaktičke modele. Nerazumevanjem potrebe za prilagođavanjem savremenom društvenom diskursu, vaspitno-obrazovne institucije insistiraju da se stvari rade na stare proverene načine (pravilo „dobre prakse”) (Zobenica i Stipančević, 2018). Da bi se obrazovni sistem modernizovao i pratio savremene društvene tokove, koji uključuju rasprostranjenu upotrebu informaciono-komunikacionih tehnologija, mora se menjati praksa unutar obrazovnih institucija, što podrazumeva i promenu uloge nastavnika i zahteva razvoj novih kompetencija (Al-Ababneh \& Alrhaimi, 2020).

Nekada se mislilo da ubrzan razvoj tehnologije i nauke i primena savremenih informaciono-komunikacionih tehnologija ugrožava poziciju nastavnika. Rezultati relevantnih pedagoških i psiholoških istraživanja tvrde suprotno. Ističu se stavovi da je nastavnik ključni nosilac globalnih promena (Ivić i saradnici, 2001), u centru obrazovne reforme, i da je neophodna rekonstrukcija njegove dosadašnje uloge, koja podrazumeva uključivanje u savremene tokove i sticanje odgovarajućih znanja i sposobnosti (Zobenica i Stipančević, 2018). Nova uloga nastavnika-podrazumeva više segmenata: pedagoški, socijalni, menadžerski i tehnički (Florence et al., 2019).

Danas nastavnik nije samo predavač i evulator, već i planer, istraživač, organizator, vodič, inovator, programer, vaspitač. Pojava novih nastavnih modela (pre svega onlajn modela) i promena uloge nastavnika zahtevaju određene kompetencije i sposobnosti za izvođenje nastave u novim uslovima.

Podučavanja u tradicionalnom i onlajn kontekstu, iako slični procesi, poseduju i određene specifičnosti po kojima se razlikuju. Dosadašnje studije pokazuju da je, kao i u tradicionalnoj školi, uloga nastavnika od presudnog značaja za kvalitet onlajn nastave (Sun \& Chen, 2016). Zbog toga je važno da nastavnici budu osposobljeni da uspešno prilagode način predavanja i pedagoške tehnike tradicionalne nastave onlajn nastavi. Da bi uspešno integrisali digitalne tehnologije u nastavni proces, nastavnici moraju dobro da vladaju veštinama u oblasti informaciono-komunikacionih tehnologija (Suárez-Rodríguez, et al., 2018). Kao jedan od važnih preduslova uspešne implementacije inovacija u nastavu i primene novih didaktičkih metoda, ističe se kontinuirana obuka nastavnog kadra u oblasti informaciono-komunikacionih tehnologija (Sharif, Marouf, et al,, 2004).

Studije koje se bave poređenjem učinka onlajn učenja i tradicionalne nastave pokazuju da onlajn nastava može biti podjednako uspešna kao tradicionalna nastava ukoliko se koriste odgovarajući nastavni metodi i tehnologije (Ristić i Mandić, 2017; Vučetić i sar., 2020). Takođe, pokazalo se i da uspešnost implementacije IKT-a u praksi zavisi od pola, starosti, nivoa obrazovanja nastavnika i mogućnosti funkcionalne 
primene, ali prethodne studije nisu podrobno razmatrale uticaj ovih faktora na obuku nastavnika (Almerich, et al., 2011).

Cilj ovog rada je da se na osnovu iskaza i stavova nastavnika sagleda i definiše profil nastavnika kojima za rad odgovara isključivo tradicionalni model nastave, i profil nastavnika koji preferiraju onlajn nastavni model ili ne prave razliku u radu između ova dva nastavna modela. Predmet istraživanja su iskustva nastavnika osnovnih škola u Srbiji o radu u modelu onlajn nastave, realizovanom u periodu pandemije COVID-19, $\mathrm{u}$ poređenju sa tradicionalnim modelom nastave.

\section{METOD ISTRAŽIVANJA I IZVORI PODATAKA}

Za potrebe ovog empirijskog istraživanja konstruisan je instrument za ispitivanje stavova nastavnika u skladu sa definisanim ciljevima i zadacima istraživanja. Upitnik se sastojao od 12 pitanja, koja su se odnosila na socio-ekonomske faktore i 16 pitanja kojim su ispitivana iskustava i stavovi nastavnika o organizaciji nastave u onlajn i tradicionalnom modelu nastave.

\section{Opis uzorka}

$\mathrm{U}$ istraživanju je učestvovalo 609 nastavnika predmetne nastave iz različitih gradova u Srbiji ${ }^{4}$. S obzirom na pol, uzorak nije bio ujednačen (24,5\% ispitanika muškog pola i $75,5 \%$ ispitanika ženskog pola). Posmatrano prema godinama radnog staža, najbrojniji su bili nastavnici koji imaju od 11 do 20 godina radnog staža $(41,5 \%)$, a potom nastavnici koji imaju do 10 godina radnog staža (31\%). Najveći broj nastavnika koji su učestvovali u istraživanju radio je u gradsko-prigradskim školama $(66,4 \%)$. Posmatrano prema naučnim oblastima u kojima su se obrazovali i koje predaju u školi, $47 \%$ ispitanika pripada prirodno-matematičkim naukama (Tabela br. 1).

Tabela 1. Karakteristike ispitanika

\begin{tabular}{|c|c|c|}
\hline Pol & $\mathrm{N}$ & $\%$ \\
\hline Muški & 149 & 24,5 \\
\hline Ženski & 460 & 75,5 \\
\hline$\sum$ & 609 & 100.0 \\
\hline Godine radnog staža & $\mathrm{N}$ & $\%$ \\
\hline do 10 & 193 & 31,7 \\
\hline $11-20$ & 253 & 41,5 \\
\hline $21-30$ & 120 & 19,7 \\
\hline preko 30 & 43 & 7,1 \\
\hline$\sum$ & 609 & 100.0 \\
\hline Obrazovanje & $\mathrm{N}$ & $\%$ \\
\hline
\end{tabular}




\begin{tabular}{|c|c|c|}
\hline Viša škola & 32 & 5,3 \\
\hline Akademske studije & 299 & 49,1 \\
\hline Master & 269 & 44,2 \\
\hline Doktorske & 9 & 1,5 \\
\hline$\sum$ & 609 & 100.0 \\
\hline Naučna oblast & $\mathrm{N}$ & $\%$ \\
\hline Prirodno-matematičke & 286 & 47 \\
\hline Društveno-humanističke & 226 & 37,1 \\
\hline Umetnost & 61 & 10 \\
\hline Sport & 36 & 5,9 \\
\hline$\sum$ & 609 & 100 \\
\hline Sredina u kojoj se nalazi škola & $\sum$ & $\%$ \\
\hline Blizina centra grada & 213 & 35 \\
\hline Širi centar grada & 126 & 20,7 \\
\hline Prigradski urbanizovani deo & 65 & 10,7 \\
\hline Prigradski seoski deo & 36 & 5,9 \\
\hline Seoska sredina & 169 & 27,8 \\
\hline$\sum$ & 609 & 100 \\
\hline & & \\
\hline
\end{tabular}

\section{REZULTATI ISTRAŽIVANJA}

S obzirom na definisan cilj i predmet istraživanja, nastavnike smo posmatrali kao dve grupe formirane prema varijabli - koji model nastave Vam više odgovara za rad. nastave

Opis karakteristika nastavnika koji su se opredelili za tradicionalni model

Prvu grupu činili su nastavnici koji su se opredeli isključivo za tradicionalni model nastave $(\mathrm{N}=493)$. S obzirom na pol, ova podgrupa prati ceo uzorak tako da je u njemu $25,6 \%$ ispitanika muškog pola i $74,4 \%$ ispitanika ženskog pola. S obzirom na godine starosti, najbrojniji su ispitanici iz srednje starosne kategorije (od 41 do 50 godina), koji čine $42,2 \%$ ispitanika; u starosnoj grupi od 31 do 40 godina ima $31 \%$ ispitanika; preko 50 godina starosti je $20,7 \%$ i do 30 godina starosti ima $6 \%$ ispitanika. Posmatrano prema godinama radnog staža, najbrojniji su nastavnici koji imaju od 11 do 20 godina radnog staža $(39,4 \%)$, a potom slede nastavnici koji imaju do 10 godina radnog staža $(33,9 \%)$, dok u kategoriju od 21 do 30 godina radnog staža spada $18,7 \%$ i najmanji procenat ispitanika ima preko 30 godina radnog staža $(8,1 \%)$. 
U odnosu na geografsku pripadnost, najveći broj nastavnika je radio u gradskim i prigradskim školama. U školama koje se nalaze u užem centru grada radilo je $35,3 \%$ nastavnika, $20,3 \%$ je radilo u školama u širem centru grada, u prigradskom urbanizovanom delu $11,2 \%$, a svega $26,6 \%$ u selu i $6,7 \%$ u prigradskom seoskom delu.

Posmatrano prema naučnim oblastima u kojima su se obrazovali i koje predaju u školi: $46,2 \%$ pripada prirodno-matematičkim naukama, 36,9\% društvenohumanističkim naukama, 9,9\% umetnosti, a 6,9\% sportu i fizičkom i zdravstvenom vaspitanju.

Nastavnici koji su se opredelili isključivo za tradicionalni model nastave kao najviši nivo obrazovanja najčešće imaju osnovne akademske studije $(48,1 \%), 45,5 \%$ nastavnika ima završene master akademske studije, doktorske studije $1 \%$ i višu školu $5,5 \%$. U trenutku ispitivanja najveći broj nastavnika $(41,2 \%)$ predavao je u sva četiri razreda (od 5. do 8. razreda), u dva razreda je predavalo je $21,5 \%$ nastavnika, u samo jednom razredu predavalo je $20,5 \%$ i u tri razreda predaje $16,8 \%$.

Opis uzorka nastavnika koji su se opredelili za onlajn model nastave ili im je svejedno po kom nastavnom modelu rade

Drugu grupu $(\mathrm{N}=116)$ činili su nastavnici koji su opredelili za onlajn model nastave ili im je svejedno po kom nastavnom modelu rade, ${ }^{5}$ od kojih je $80,2 \%$ bilo ženskog pola i $19,8 \%$ ispitanika muškog pola. S obzirom na godine starosti, najbrojniji su bili ispitanici iz srednje starosne kategorije (41-50), koji čine 39,1\% ispitanika, između 31 i 40 godina je imalo $33,9 \%$, preko 50 godina je imalo $18,7 \%$ i do 30 godina starosti je imalo $8,3 \%$ ispitanika. Ako uzorak posmatrano prema godinama radnog staža, najbrojniji su bili nastavnici koji su imali od 11 do 20 godina radnog staža $(50,9 \%)$, a zatim nastavnici koji su imali od 21 do 30 godina radnog staža $(24,1 \%)$, dok je u kategoriju do 10 godina spadalo $22,4 \%$ ispitanika. Najmanji procenat ispitanika je imao preko 30 godina radnog staža $(2,6 \%)$.

Najveći broj nastavnika je radio u gradskim i prigradskim školama: $33,6 \%$ škola nalazi se u užem centru grada, $22,4 \%$ u širem centru grada, u prigradskom urbanizovanom delu $8,6 \%$, a svega $6,7 \%$ u prigradskom seoskom delu, dok $32,8 \%$ radi u seoskim školama.

Posmatrano prema naučnim oblastima u kojima su se obrazovali i koje predaju u školi: 50,2\% ispitanika pripada prirodno-matematičkim naukama, 37,9\% društvenohumanističkim naukama, 10,3\% umetnosti, a 1,7\% sportu i fizičkom i zdravstvenom vaspitanju. Kao najviši stepen obrazovanja nastavnici su u najvećem broju imali završene osnovne akademske studije $(53,4 \%) ; 38,3 \%$ nastavnika je imalo završene master akademske studije; doktorske studije 3,4\% i višu školu 4,3\% nastavnika. U trenutku ispitivanja najveći broj nastavnika je predavao u sva četiri razreda (od 5. do

5 Ispitanike koji su se opredelili za opciju nema razlike, posmatrali smo zajedno sa ispitanicima iz grupe onlajn model, jer se u prvoj grupi nalaze ispitanici koji isključivo preferiraju samo tradicionalni model nastave. 
8. razreda - 53,4\%), a $25,9 \%$ nastavnika je predavalo u dva razreda, dok je procenat nastavnika koji su predavali u jednom i u tri odeljenja ujednačen, po $10,3 \%$ nastavnika.

$\mathrm{Na}$ osnovu prikupljenih podataka o samoproceni nastavnika koji preferiraju isključivo tradicionalni model nastave, kao i onih koji su se opredelili za onlajn model nastave ili im je svejedno u kom nastavnom modelu rade - definisane su dve perspektive, tj. dva profila nastavnika i izdvojene kompetencije po kojim se oni razlikuju.

\section{Profili nastavnika u zavisnosti od (samo)procene}

U zavisnosti od opredeljenja nastavnika za određeni nastavni model, izvršena je procena svojstava nastavnog procesa od strane nastavnika u obe skupine - grupe nastavnika koji preferiraju isključivo tradicionalni nastavni model (T) i grupe nastavnika koji preferiraju onlajn nastavni model ili im je svejedno u kom nastavnom modelu rade $(\mathrm{O})$, Tabela 2.

Tabela 2. Samoprocena nastavnika: tradicionalni-onlajn model nastave

\begin{tabular}{|l|c|c|c|c|c|}
\cline { 3 - 6 } \multicolumn{2}{c|}{} & $\begin{array}{c}\text { Tradicionalna } \\
\text { nastava }\end{array}$ & $\begin{array}{c}\text { Onlajn } \\
\text { nastava }\end{array}$ & Nema razlke & Ukupno \\
\hline \multirow{2}{*}{ Veći kvalitet nastave } & $\mathrm{T}$ & 95,9 & 1,0 & 3,0 & 100 \\
\cline { 2 - 6 } & $\mathrm{O}$ & 54,3 & 6,0 & 39,7 & 100 \\
\hline \multirow{2}{*}{ Veći intezitet nastave } & $\mathrm{T}$ & 88,6 & 4,9 & 6,5 & 100 \\
\cline { 2 - 6 } & $\mathrm{O}$ & 37,9 & 19,0 & 43,1 & 100 \\
\hline \multirow{2}{*}{$\begin{array}{l}\text { Više vremena za } \\
\text { administrativnu } \\
\text { pripremu }\end{array}$} & $\mathrm{T}$ & 19,1 & 46,5 & 34,5 & 100 \\
\cline { 2 - 6 } Priprema nastave & $\mathrm{O}$ & 18,1 & 31,9 & 50,0 & 100 \\
\cline { 2 - 6 } zahteva više vremena & $\mathrm{T}$ & 17,8 & 57,8 & 24,3 & 100 \\
\cline { 2 - 6 } & $\mathrm{O}$ & 11,2 & 53,4 & 35,3 & 100 \\
\hline $\begin{array}{l}\text { Organizovanje } \\
\text { grupnog rada učenika }\end{array}$ & $\mathrm{T}$ & 84,2 & 6,3 & 9,5 & 100 \\
\cline { 2 - 6 } & $\mathrm{O}$ & 73,3 & 12,9 & 13,8 & 100 \\
\hline
\end{tabular}

$\mathrm{T}=$ tradicionalni nastavni model $(\%), \mathrm{O}=$ onlajn nastavni model $(\%)$

Posmatrano na nivou celog uzorka, oko 96\% ispitanika u grupi opredeljenih za tradicionalni nastavni model smatra da je nastava kvalitetnija kada se primenjuje ovaj model, dok isto smatra oko 54\% ispitanika u grupi nastavnika čiji je izbor bio onlajn nastavni model ili im je svejedno u kom nastavnom modelu rade.

Što se tiče intenziteta nastave, ogromna većina ispitanika koji preferiraju tradicionalni tip nastave $(88,6 \%)$, smatra tradicionalnu nastavu intenzivnijom u odnosu na onlajn nastavu. Najveći procenat ispitanika $(43,1 \%)$ čiji je izbor bio onlajn nastava 
ili im je svejedno o kom tipu nastave se radi, smatra da nema razlike u intenzitetu nastave između ova dva nastavna modela.

U pogledu vremena koje zahtevaju administrativne pripreme nastave, rezultati su ujednačeni za obe grupe nastavnika. Tradicionalni nastavni model je ocenjen kao zahtevniji od strane približno istog procenta u obe grupe nastavnika $(19,1 \%$ i 18,1\%). Onlajn nastavni model je ocenjen kao zahtevniji u pogledu administracije od strane $46 \%$ nastavnika koji preferiraju tradicionalni tip nastave, u odnosu na oko $32 \%$ onih koji biraju onlajn nastavu. Čak 50\% nastavnika koji biraju onlajn nastavu smatra da nema razlike $u$ administrativnim obavezama između ova dva nastavna modela .

Obe grupe smatraju da onlajn nastava zahteva više izdvojenog vremena za pripremu časa $(57,8 \%$ i $53,4 \%)$.

Kooperativni model učenja lakše je organizovati kada se nastava realizuje na tradicionalan način u školi smatra $84,2 \%$ nastavnika koji preferiraju tradicionalnu nastavu, nasuprot $73,3 \%$ onih koji preferiraju onlajn nastavu. Pri tumačenju ovih rezultata treba imati na umu složnost fenomena kooperativnog učenja. Potrebno je primeniti različite kriterijume prilikom formiranja kooperativnih grupa, a pritom i zadovoljiti druge organizacione zahteve kooperativnog učenja koji to znanje treba da u situaciji učenja učine funkcionalnim, deljivim, a zatim i da ga unaprede. Takođe, po kom će se kriterijumu učenici grupisati zavisi od prirode predmeta (Vasojević, 2011).

Da bi se ustanovilo da li postoji statistička razlika između stavova nastavnika o tradicionalnom i onlajn nastavnom modelu, posmatrali smo varijable: Kompetencije za onlajn nastavu; Starost; Iskustvo; Edukacija i trajanje obuke. T-test nezavisnih uzoraka pokazuje da nastavnici u zavisnosti od kompetencija za izvođenje onlajn nastave (Kompetencije za onlajn nastavu, $\mathrm{t}=-8,798, \mathrm{p}<0,001$ ) i trajanja prethodne obuke u oblasti primene informaciono-komunikativnih tehnologija (Edukacija $i$ trajanje obuke, $\mathrm{t}=-3,012, \mathrm{p}=0,003$ ) - različito vrednuju tradicionalni i onlajn model nastave. To znači da izbor tradicionalnog ili onlajn nastavnog modela zavisi od toga koliko se nastavnik oseća kompetentnim za izvođenje onlajn nastave i od dužine trajanja prethodne obuke za onlajn nastavu koju je pohađao.

\section{DISKUSIJA}

Rezultati istraživanja pokazali su da u odnosu na iskustva nastavnika tokom rada u onlajn nastavnom modelu za vreme pandemije postoji razlika u stavovima o načinu i kvalitetu rada u onlajn i tradicionalnoj nastavi. Dakle, da postoje nastavnici koji preferiraju tradicionalni nastavni model, i nastavnici koji preferiraju onlajn nastavni model ili im je svejedno u kom nastavnom modelu rade. Takođe, pokazalo se da na izbor nastavnog modela utiče to koliko se nastavnik oseća osposobljenim za podučavanje u tom nastavnom modelu, odnosno kolike su, prema samoproceni sposobnosti, njegove kompetencije da sprovodi taj vid nastave, što zapravo zavisi od osposobljenosti nastavnika za izvođenje onlajn nastave i dužine trajanja prethodne IKT obuke. Ova saznanja odgovaraju saznanjima prethodnih studija o vezi između 
samoprocene sposobnosti i uspešnosti primene datih veština u praksi (Buchanan, et al., 2013). Nastavnici koji svoje kompetencije u oblasti informaciono-komunikacionih tehnologija ocenjuju kao visoke, u većoj meri primenjuju IKT u nastavi (SuárezRodríguez, et al., 2018). Takođe, odgovaraju saznanjima studija koje ističu važnost obuke nastavnika u oblasti IKT-a, čiji rezultati pokazuju da nastavnici koji nisu pohađali obuku u ovoj oblasti u neznatnoj meri koriste IKT u nastavi, kao i studija koje ističu važnost osposobljavanja nastavnika kroz primenu naučenog u praksi, kako se pokazalo da je za uspešan ishod obuke neophodna mogućnost primene u praksi (Di Pietro et al.,2008).

U odnosu na karakteristike nastavnika koji preferiraju tradicionalni ili onlajn nastavni model, dobijeni su sledeći rezultati:

U odnosu na varijablu pola, više žena se opredeljuje za drugi model (onlajn ili nema razlike) nastave ( $\check{Z}=80,2 \%)$. Starosna kategorija i radno iskustvo ne utiču na izbor preferiranog modela nastave ( $\mathrm{T}=73,2 \%$ nastavnika starosne kategorije $31-50$ godina i $73 \%$ koji preferiraju onlajn model nastave, dok statistički značajnih razlika nema u zavisnosti od geografskog položaja škole). S obzirom na naučne oblasti, za onlajn nastavu se izjasnilo više nastavnika koji pripadaju prirodno-matematičkim naukama (50,2\%), nasuprot $46 \%$ nastavnika koji su preferilali tradicionalni model nastave. Tradicionalni model nastave je preferiralo više nastavnika koji predaju fizičko i zdravstveno vaspitanje, što se može shvatiti kao očekivano jer je reč o specifičnom vaspitno-obrazovnom području i za ostvarivanje ciljeva i zadatka nastave potrebno je obezbediti posebne uslove (oprema, prostor, sprave, rekvizitim, kao i praćenje nastavnika).

Postoji razlika u odnosu na varijablu broja razreda u kojima su nastavnici predavali. Znatno veći procenat nastavnika koji predaju u sva 4 razreda se opredelio za onlajn nastavu $(53,4 \%)$, nasuprot $41,2 \%$ nastavnika koji su se opredelili za tradicionalni model.

U pogledu kvaliteta nastave, skoro svi nastavnici koji preferiraju tradicionalni nastavni model smatraju ovaj model boljim, dok samo polovina onih koji preferiraju onlajn nastavni model smatraju onlajn model boljim. U pogledu intenziteta nastave, skoro $90 \%$ nastavnika koji preferiraju tradicionalni nastavni model smatra da tradicionalna nastava podrazumeva veći intenzitet nastave, dok manje od polovine nastavnika koji preferiraju onlajn nastavni model smatra ovaj vid nastave intenzivnijim. U pogledu administrativnih priprema i pripreme časa, stavovi i mišljenja nastavnika iz obe grupe su prilično ujednačeni - nastavnici iz obe grupe smatraju da je onlajn nastavni model zahtevniji po pitanju vremena. Ovo je u skladu sa saznanjima prethodnih studija koje su pokazale da realizacija onlajn nastave zahteva više vremena (Sun \& Chen, 2016), kao i saznanjima studija којe ističu da je potrebno da nastavnici ulože više vremena u pripremu nastavnog materijala (Vučetić i sar, 2020). U pogledu organizacije grupnog rada učenika, velika većina nastavnika iz obe grupe smatra da tradicionalni model nudi bolje uslove za zajednički rad učenika, što se donekle poklapa sa teorijskim istraživanjima (Vasojević, 2011). 


\section{ZAKLJUČAK}

U kontekstu savremene škole, imajući u vidu rasprostranjenost informacionokomunikacionih tehnologija i prepoznate prednosti njihove implementacije $u$ nastavni proces, može se zaključiti da bi razvoj obrazovnog sistema trebalo da se oslanja na prednosti savremenih digitalnih tehnologija, koje bi omogućile aktivnije učestvovanje učenika u nastavi i bolje usvajanje funkcionalnog znanja. Rezultati istraživanja pokazali su da, nezavisno od načelnog opredeljenja za tradicionalni ili onlajn nastavni model - kada je u pitanju kvalitet nastave, velika većina nastavnika daje prednost tradicionalnom nastavnom modelu. Takođe, pokazano je da stavovi nastavnika i izbor nastavnog modela koji preferiraju zavisi od toga koliko se nastavnik oseća kompetentnim za izvođenje onlajn nastave, kao i od dužine trajanja prethodne obuke za rad u onlajn nastavi. Možemo zaključiti da je za uvođenje informacionokomunikacionih tehnologija i poboljšanje kvaliteta nastavnog procesa, odnosno za kvalitetnu primenu onlajn nastavnog modela, potrebno sprovesti sistematičnu i svrsishodnu obuku nastavnog kadra.

\section{LITERATURA}

Almerich, G., Suárez-Rodríguez, J. M., Belloch, C., \& Rosa, M. B. (2011). Training needs of teachers in ICT: training profiles and elements of complexity. RELIEVE, 17(2), 1-27. http://www.uv.es/RELIEVE/v17n2/RELIEVEv17n2_5eng.htm

Buchanan, T., Sainter, P., \& Saunders, G. (2013). Factors affecting faculty use of learning technologies: implications for models of technology adoption. Journal of Computing in Higher Education, 25(1), 1-11. http://dx.doi.org/10.1007/s12528013-9066-6

Di Pietro, M., Ferdig, E. R., Black, W. E., \& Preston, M. (2008). Best practices in teaching K-12 online: Lessons learned from Michigan Virtual School teachers. Journal of Interactive Online Learning, 7(1), 10-35. Retrieved from http://iols. gmu.edu/assets/761/Article2e.pdf

Ivić, I., Pešikan, A., Janković, S., i Kijevčanin, S. (2001). Aktivno učenje. Beograd: Institut za psihologiju.

Lasić, K. (2020). Uloge nastavnika u tradicionalnoj i kvalitetnoj školi. Pregledni znanstveni članak, 3(2), 101-110.

Maksimović, Z. J., i Osmanović, S. J. (2018). Značaj medijske kulture za alternativno obrazovanje. Filozofija medija: mediji i alternativa, 22, 91-103. Preuzeto sa https://pefja.kg.ac.rs/wp-content/uploads/2018/09/10-Jelena-\%C5\%BD.-Maksimovi\% C4\%87-Jelena-S.-Osmanovi\%C4\%87-ZNA\%C4\%8CAJ-MEDIJSKEKULTURE.pdf

Florence, M., Ritzhauptb, A., Kumar, S., \& Budhrania, K. (2019). Award-winning faculty online teaching practices: Course design, assessment and evaluati- 
on, and facilitation. The Internet and Higher Education, 42, 34-43. https://doi. org/10.1016/j.iheduc.2019.04.0017

Pavlović, A., Ivanišević, A., Radišić M., i Lošonc, A. (2021). Uticaj Covid-19 i online učenja na visoko obrazovanje u Srbiji. U: Katić, V. (ured.), XXVII Skup Trendovi razvoja: , on-line nastava na Univerzitetima” (str. 189-192). Novi Sad, $15-18$.

Ristić, M., i Mandić, D. (2017). Obrazovanje na daljinu. Beograd: Učiteljski fakultet u Beogradu.

Sun, A., \& Chen, X. (2016). Online Education and Its Effective Practice: A Research Review. Journal of Information Technology Education: Research, 15, 157-190. https://doi.org/10.28945/3502

Suárez-Rodríguez, J., Almerich, G., Orellana, N., et al. (2018). A basic model of integration of ICT by teachers: competence and use. Education Tech Research Dev, 66, ISSN 1165-1187. https://doi.org/10.1007/s11423-018-9591-0

Sharif, B. A., Marouf, H., \& Ali, N. A. (2020). The Role of Strategic Transformation in the University Education Management. The Scientific Journal of Cihan University - Sulaimaniya, 4(2), 140-161. ISSN 2520-7377.

Swan, K. (2004). Learning online: current research on issues of interface, teaching presence and learner characteristics. In: Bourne J. \& Moore J. C. (Ed.), Elements of Quality Online Education, Into the Mainstream (pp. 63-79). Needham, MA: Sloan Center for Online Education.

Šejtanić, S. (2009). Uloga i stil rada nastavnika u savremenoj školi. Didaktički putokazi, časopis za nastavu teoriju i praksu, Pedagoški zavod i pedagoški fakultet u Zenici, 66-69. ISSN 1512-5998.

Vasojević, N.A., Kirin, S., i Vučetić, I. (2020). Aplikacije u nastavi u doba COVID19Obrazovanje i tehnološke inovacije. U: Pašić, G. (ured.). 7. Zbornik radova, VII međunarodni naučno-stručni skup ,,Tehnološke inovacije - Generator privrednog razvoja“ (str. 27-36). Banja Luka: Savez inovatora Republike Srpske.

Vasojević, N. (2011). Kolaborativno učenje u državnim i privatnim osnovnim školama. Diplomski rad. Fakultet pedagoških nauka u Jagodini, Univerzitet u Kragujevcu.

Vučetić, I., Vasojević, N., i Kirin, S. (2020). Mišljenje učenika srednjih škola u Srbiji o prednostima onlajn učenja tokom pandemije Covid-19. Nastava $i$ vaspitanje, 69(3), 345-359.

Zobenica, N., Stipančević, A. (2017). Uloga i kompetencije nastavnika u globalnom društvu. Pedagoška stvarnost, 63(2), 107-119. DOI: https://doi.org/10.19090/ ps.2017.2.107-119.

Wang, Q. (2011). Application of Practice of Teaching Reform of Open Educational Resources in Environmental Science. 2011 International Conference on Economic, Education and Management (icem 2011), II, 83-85. 


\section{The Serbian primary school teachers' profiles regarding the preference for a teaching model during the COVID-19 pandemics}

Summary: The quality of the teaching process highly depends on teachers and their qualifications,
and the teacher's role plays a very important part in the implementation of the new teaching
methods. The results presented in this paper are part of the quantitative study which investigated the
primary teachers' perception of the online teaching model that has been realized in Serbia during
the COVID-19 pandemic, in comparison to the traditional teaching model.
The paper aims to define and present the teachers' profiles, based on their preference for a certain
teaching model: the profile of the teachers who prefer working in the traditional teaching model,
and the profile of the teachers who prefer working in the online teaching model, or do not make
any difference between the two, based on the professional data and their statements and attitudes
regarding the comparison of traditional and online teaching models. It was assumed that the teachers
with less work experience, more professional training and higher education level would generally
prefer the online teaching model. For the research purposes, the specialized two-part questionnaire
was designed. The first part included questions concerning the socio-demographic background,
while the second part investigated the teachers' attitudes towards the characteristics of the teaching
process in both traditional and online teaching models. The independent sample $t$ - test was used
to estimate the influence of previous training on the choice of the preferred teaching model. The
research was conducted during January and February 2021 . The research sample included 609
examinees. The research results showed that the choice of the preferred teaching model depends on
the self-assessment of the teachers' competencies required for the online teaching model, as well
as on the duration of the training in the field of Information and Communication Technologies, as
a part of the regular professional improvement training. The initial assumption was only partially
confirmed by the research results. Keywords: traditional teaching, online teaching, teachers' profiles, teachers' competencies, COVID-19 